\title{
Not Just Fat: The Structure and Function of the Lipid Droplet
}

\author{
Toyoshi Fujimoto ${ }^{1}$ and Robert G. Parton ${ }^{2}$ \\ ${ }^{1}$ Department of Anatomy and Molecular Cell Biology, Nagoya University Graduate School of Medicine, \\ Nagoya 466-8550, Japan \\ ${ }^{2}$ The University of Queensland, Institute for Molecular Bioscience and Centre for Microscopy and \\ Microanalysis, Brisbane, QLD 4072, Australia \\ Correspondence: tfujimot@med.nagoya-u.ac.jp
}

Lipid droplets (LDs) are independent organelles that are composed of a lipid ester core and a surface phospholipid monolayer. Recent studies have revealed many new proteins, functions, and phenomena associated with LDs. In addition, a number of diseases related to LDs are beginning to be understood at the molecular level. It is now clear that LDs are not an inert store of excess lipids but are dynamically engaged in various cellular functions, some of which are not directly related to lipid metabolism. Compared to conventional membrane organelles, there are still many uncertainties concerning the molecular architecture of LDs and how each function is placed in a structural context. Recent findings and remaining questions are discussed.

$\mathrm{L}_{\mathrm{n}}^{\mathrm{in}}$ ipid droplets (LDs) were recognized as a Lmere deposit of lipid esters for many years. Recently, LDs have been redefined as authentic organelles that are actively engaged in multiple functions, and these have been reviewed in many recent articles (Murphy 2001; Martin et al. 2006; Ducharme et al. 2008; Fujimoto et al. 2008; Goodman 2008; Olofsson et al. 2008; Thiele et al. 2008; Murphy et al. 2009; Walther et al. 2009; Beller et al. 2010). The name, lipid droplets, implies the opposite: a static and inert nature. Alternative names have been proposed, but lipid droplet is now a generally agreed nomenclature (Martin et al. 2006).

LDs are intimately related to many aspects of lipid metabolism. The lipid storage function of LDs is most conspicuous in white adipocytes, which have a gigantic unilocular LD. The regulation of the process of lipid storage and utilization has been the focus of many studies because of the prevalence of obesity, type II diabetes, and metabolic syndrome in the modern world.

Besides the canonical lipid-related function, various new functions have been ascribed to LDs more recently, including some that do not appear to be directly related to lipid metabolism. However, both the canonical and noncanonical functions of LDs, are rooted in the unique architecture of LDs. In contrast to other organelles that have aqueous content within a phospholipid bilayer membrane, the basic structure of LDs is thought to be a mass of lipid esters

Editor: Kai Simons

Additional Perspectives on The Biology of Lipids available at www.cshperspectives.org

Copyright (C) 2011 Cold Spring Harbor Laboratory Press; all rights reserved; doi: 10.1101/cshperspect.a004838

Cite this article as Cold Spring Harb Perspect Biol 2011;3:a004838 
covered by a phospholipid monolayer (Murphy et al. 1999; Tauchi-Sato et al. 2002). In this article, we first review what is known about LD structure and then discuss various functions. We review this information by considering the extent to which the functions can be understood based on the current structural paradigm.

\section{STRUCTURE OF LIPID DROPLETS}

By microscopy, LDs are observed as round structures (Fig. 1A). Their diameters generally range from $0.1-5 \mu \mathrm{m}$ in nonadipocytes, but they can reach more than $100 \mu \mathrm{m}$ in the white adipocyte. The LD surface is not bound with a conventional unit membrane but delimited by a phospholipid monolayer (Fig. 1B) (TauchiSato et al. 2002). LD phospholipids include phosphatidylcholine (PC), phosphatidylethanolamine (PE), phosphatidylinositol, lysoPC, and lysoPE, and some of them have unique properties (Leber et al. 1994; Tauchi-Sato et al. 2002; Bartz et al. 2007). Free cholesterol (FC) is also likely to be in the LD surface layer (Prattes et al. 2000), but the possibility that some phospholipids and FC exist in the core cannot be excluded (Hevonoja et al. 2000).

The LD core is made of lipid esters. In white adipocytes, triglycerides (TG) are predominant, but in most cell types, TGs and cholesterol esters
(CE) coexist in various ratios. Conventional electron microscopy (EM) does not show any demarcation in the core, but TG and CE may be segregated from each other at least in some circumstances (Fig. 2A,B) (Czabany et al. 2008; Cheng et al. 2009). A similar segregation may also occur among TGs because they have vastly different melting temperatures depending on fatty acid composition (Kaye et al. 1995). Concentric lines observed by cryoelectron microscopy (Fig. 2A) (Tauchi-Sato et al. 2002) and onion skin-like fracture faces in freeze-fracture electron microscopy (Baba et al. 1995; Tauchi-Sato et al. 2002) might reflect such partitioning among lipid esters. Membrane-like structures were also observed in the LD core of some cell types (Fig. 2C) (Wan et al. 2007; Singh et al. 2009).

Proteins are generally thought to be embedded in or adherent to the LD surface. However, some morphological studies show the presence of proteins, including soluble ones, in the LD core (Dvorak et al. 1992; Bozza et al. 1997; Robenek et al. 2004, 2005). It is not plausible that hydrophilic proteins exist alone in the core, but amphiphilic proteins may complex with phospholipids to make structures compatible with the hydrophobic environment.

This suggests that the current paradigm of LD structure, that is, a homogeneous lipid ester core covered by a phospholipid monolayer studded
A

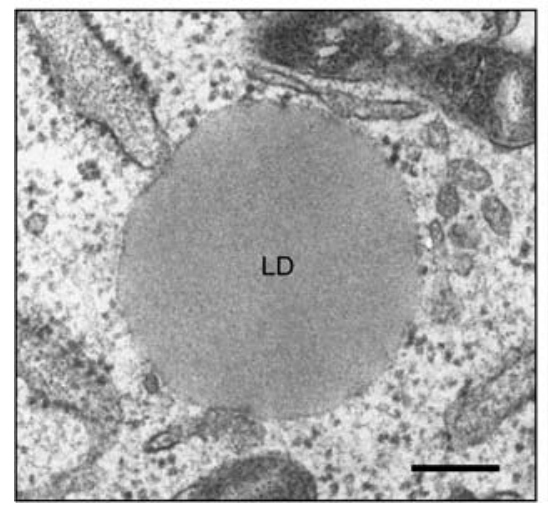

B

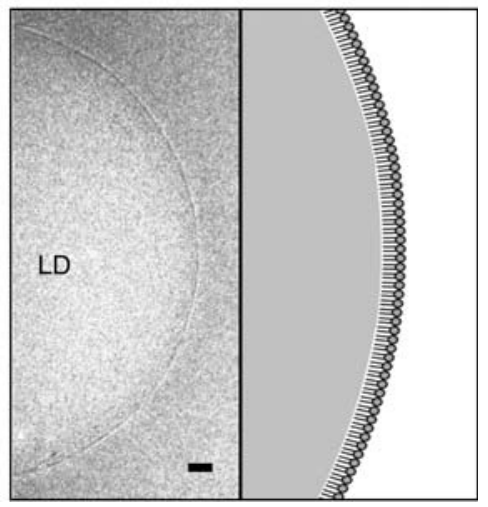

Figure 1. The current paradigm of the LD structure. (A) Conventional electron microscopy. LDs are observed as spherical structures with no internal structure and are not delimited by the conventional unit membrane. Bar, $200 \mathrm{~nm}$. (B) Cryoelectron microscopy of the isolated LD. The LD surface is seen as a single electron-dense line, which is probably derived from a row of phosphorus atoms in the phospholipid monolayer. Bar, $20 \mathrm{~nm}$. 

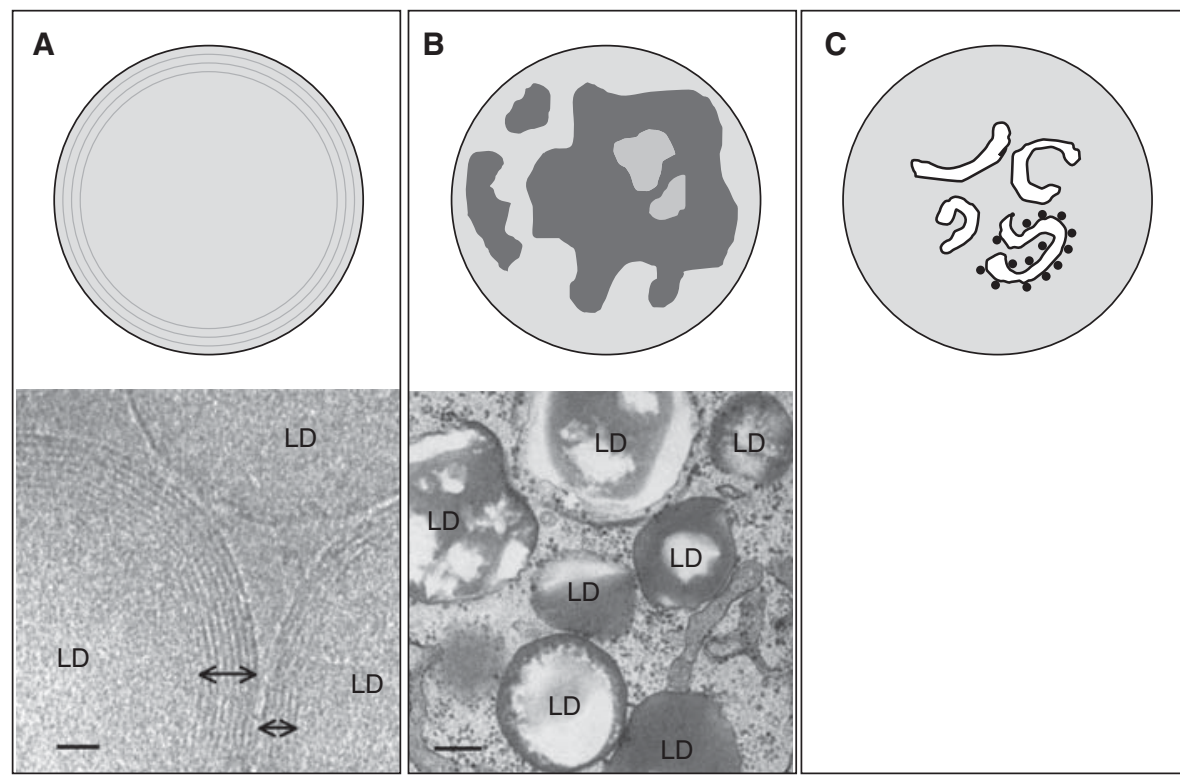

Figure 2. Possible structures in the LD core. $(A)$ Concentric lipid ester layers. Cholesterol ester was proposed to make concentric layers in the LD core. The concentric lines observed by cryoelectron microscopy (shown by bidirectional arrows) may correspond to the cholesterol ester layer boundaries. Bar, $20 \mathrm{~nm}$. (B) Irregular partitioning of lipid esters. The electron micrograph shows that cholesterol esters (low electron density) and triglycerides (high electron density) are segregated in LDs. In this example, cells were sequentially loaded with cholesterol and docosahexanoic acid (Cheng et al. 2009). Bar, $200 \mathrm{~nm}$. (C) Internal membrane-like structures in the core. The membranous structures are occasionally studded with ribosomes suggesting their ER origin.

with proteins, is thermodynamically sound and should explain the basic characteristics of LDs. It must be emphasized, however, that the presence of additional features cannot be excluded.

\section{BIOGENESIS OF LIPID DROPLETS}

Although several hypotheses on the process of LD formation have been proposed and discussed (Wanner et al. 1981; Murphy et al. 1999; Zweytick et al. 2000; Waltermann et al. 2005; Ploegh 2007) none are sufficiently proven or refuted by the available experimental data. The classical model postulates budding of the lipid ester globule covered by the cytoplasmic leaflet of the ER membrane and explains the basic LD structure easily (Murphy et al. 1999). The "hatching" model hypothesizes a bicellar structure (Ploegh 2007) and can explain the presence of transmembrane ER proteins in isolated LDs. However, it should be noted that both biochemical and light microscopic methods are insufficient to definitively prove association of proteins with bona fide LDs rather than associated membranes. Another viable model is that lipid esters accumulate in the membrane of small vesicles and eventually obliterate the lumen (Walther et al. 2009).

The last steps of TG and CE synthesis are catalyzed by diacylglycerol acyltransferases (DGATs) and acyl-CoA:cholesterol acyltranserases (ACATs), respectively, which reside in the ER (Fig. 3; Yen et al. 2008; Chang et al. 2009). Hydrophobic lipid esters are likely to be deposited inside the ER membrane, although wax esters of bacterial LDs are thought to accumulate on the membrane surface (Waltermann et al. 2005). A small amount of lipid esters can be assimilated in the phospholipid bilayer (Hamilton et al. 1982; Hamilton 1989), but when the solubility limit is exceeded, lipid esters are thought to precipitate out between the two leaflets. This state, i.e., lipid ester deposits in the membrane, has been observed only in rare 


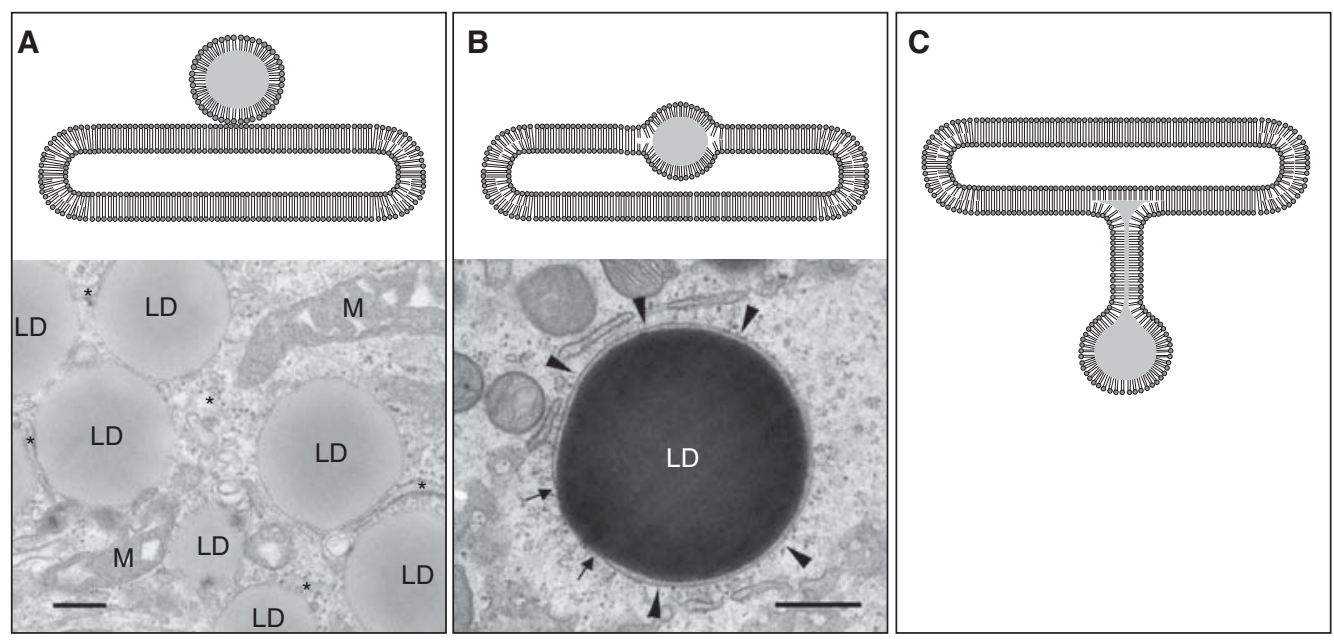

Figure 3. Possible relationship of LDs and the ER. $(A)$ Close apposition. LDs and the ER $\left(^{*}\right)$ are often located closely and may make membrane contacts. Mitochondria $(\mathrm{M})$ are also frequently adjacent to LDs. Bar, $200 \mathrm{~nm}$. (B) Intercalation. Huh7 cells loaded with docosahexanoic acid show large LDs intercalated in the ER membrane (arrowheads). The arrows indicate the points in which the ER membrane is continuous with an LD. Bar, $200 \mathrm{~nm}$. (C) Connection by a membrane stalk. The stalk may be a conduit of lipid esters between the LD and the ER membrane.

instances (Fig. 3B) (Ohsaki et al. 2008), suggesting that the structure is difficult to preserve by conventional methods and/or that nascent LDs quickly separate from the ER before they become large enough to be observed microscopically (Mountford et al. 1988; Hakumaki et al. 2000).

It is noteworthy that nonpolar lipids are not always incorporated into LDs but can be stored elsewhere. A large amount of squalene, for example, can be stored in the microsomal membrane of yeast without compromising cell functionality (Spanova et al. 2010). By depletion of adipocyte differentiation-related protein (ADRP) or by inhibition of group IVA cytosolic phospholipase $A_{2}$, TG levels in LDs decreased and shifted to the microsome (Chang et al. 2006; Gubern et al. 2008). An in vitro experiment suggested the involvement of phospholipase $\mathrm{D}$ in the LD formation process (Marchesan et al. 2003). The results suggest that LD formation does not occur spontaneously because of lipid ester accumulation but require some active mechanism.

Whatever the mechanism of LD formation, new LDs should grow such that their surface and the volume is coordinated proportionally (Fujimoto et al. 2008). In fact, suppression of PC synthesis in Drosophila cells induced mutual LD fusion to decrease the surface-to-volume ratio, indicating that $\mathrm{PC}$ availability is a critical regulatory factor in LD growth (Guo et al. 2008). A similar enlargement of LDs was also reported in mammalian cells deficient in CTP: phosphocholine cytidylyltransferase- $\alpha$, the key regulatory enzyme of the Kennedy pathway for PC synthesis (Jacobs et al. 2008). The importance of phospholipids in LD growth was also highlighted in studies on yeast Fld1p (Szymanski et al. 2007; Fei et al. 2008), which is a functional homolog of mammalian seipin encoded by the Berardinelli-Seip Congenital Lipodystrophy Type 2 gene (Magre et al. 2001). Loss of Fld1p was shown to enhance LD fusion and induce supersized LDs, probably by altering acyl chain compositions of phospholipids (Szymanski et al. 2007; Fei et al. 2008).

Mutual fusion catalyzed by the SNARE proteins, SNAP23, syntaxin-5, and VAMP4, is a possible mechanism of $\mathrm{LD}$ growth (Bostrom et al. 2007), however, it may not be an exclusive LD growth mechanism in mammalian cells as 
only a low frequency of fusion was observed by live imaging (Wolins et al. 2005; Thiele et al. 2008). Repetitive fusion also does not readily explain the uniform incorporation of newly formed TG to existing LDs (Cheng et al. 2009). Other mechanisms such as local lipid ester synthesis in and/or around individual LDs may be also involved in the growth process (Kuerschner et al. 2008).

It is likely that at least some LDs remain tethered to the ER. The bidirectional movement of some proteins between LDs and the ER membrane suggests a close structural relationship (Pol et al. 2005; Turro et al. 2006; Zehmer et al. 2009). However, it has not been shown unequivocally that normal LDs retain membrane continuity with the ER as plastoglobules do with the thylakoid membrane (Fig. 3C; Austin et al. 2006).

\section{THE LIPID DROPLET PROTEOME}

For the last several years, a large number of proteins have been identified by proteomic analyses of LDs obtained from a wide variety of organisms. The results are discussed in detail in a recent review (Hodges et al. 2009). Because of ample lipid ester content, LDs have exceptionally high buoyancy and thus can be easily separated from other organelles. Nonetheless, LD preparation cannot be free from "contamination" for two reasons. First, LDs are often very closely associated with other organelles (Fig. 3A; Novikoff et al. 1980; Stemberger et al. 1984; Blanchette-Mackie et al. 1995), thus proteins found in isolated LDs may be derived from adhering structures, especially when they are found in both LDs and other fractions. Second, the exposure of lipid esters to an aqueous environment by mechanical disruption may cause artificial adherence of unrelated proteins by hydrophobic interaction (Fujimoto et al. 2006). These possibilities need to be carefully examined for individual proteins.

Methods based on other disciplines may help resolve these uncertainties. However, the close proximity of LDs and other organelles means that light microscopy is not always definitive. Immunoelectron microscopy has the required spatial resolution, but it is often difficult to preserve the LD structure because of a lack of an appropriate chemical fixative for lipids. Therefore, a combination of various cell biological techniques is required to determine endogenous protein distribution in a quantitative manner.

\section{LIPID DROPLETS IN ADIPOCYTES}

The major function of LDs is lipid storage. Stored lipid esters are mobilized for $\beta$-oxidation, membrane biogenesis, protein modification, synthesis of lipoproteins, steroids, and other lipid mediators, etc. PAT proteins play critical roles in regulating the storage and utilization of lipids, and their functions in adipocytes have been reviewed extensively in many recent articles (Brasaemle 2007; Bickel et al. 2009). Therefore, in this article adipocyte LDs will be discussed briefly and only as a prototype to discuss general LD function in later sections.

PAT was named after perilipin, ADRP (also called adipophilin, ADFP), and tail-interacting protein of $47 \mathrm{kDa}$ (TIP47), which were proposed to be renamed as PLIN1, PLIN2, and PLIN3 (Kimmel et al. 2010). Together with S3-12 (PLIN4) and OXPAT/MLDP/LSDP5 (PLIN5), they constitute the PAT protein family. Perilipin was found as the first LD protein and is expressed in adipocytes and steroidogenic cells (Greenberg et al. 1991). S3-12 is also largely restricted to adipocytes, whereas ADRP and TIP47 are found ubiquitously, and OXPAT/ MLDP/LSDP5 is mainly expressed in organs engaged in active fatty acid oxidation, such as liver, muscle, and brown adipose tissue.

Perilipin A, a perilipin isoform, is the major regulatory factor of lipolysis in white adipocytes. Lipolysis is catalyzed by adipose triglyceride lipase (ATGL) and hormone-sensitive lipase (HSL) enzymes that effectively hydrolyze TG and diacylglycerol (DG), respectively (Zimmermann et al. 2009). On lipolytic stimulation, perilipin A is phosphorylated by cAMP-dependent protein kinase and releases CGI-58, which then activates ATGL (Subramanian et al. 2004; Lass et al. 2006; Granneman et al. 2007). Perilipin A also assists HSL translocation and 
activation at the LD surface (Sztalryd et al. 2003).

Under resting conditions, perilipin A is thought to function as a barrier to protect lipid esters from lipases, but it is assumed to cover a relatively small area of the LD surface (Londos et al. 1999). Moreover, even when perilipin is absent, lipases may not be able to hydrolyze lipid esters effectively as far as they are covered by a continuous phospholipid monolayer. In this respect, it is notable that TIP47 has apolipoprotein-like properties and can reorganize liposomes into small lipid discs (Bulankina et al. 2009). PAT proteins may regulate lipolysis by modulating the LD surface structure and changing the accessibility of lipid esters to the lipases.

Another phenomenon that is ascribed to perilipin $\mathrm{A}$ is the appearance of microsized LDs after lipolytic stimulation (Marcinkiewicz et al. 2006). Disruption of a sphere into many small spheres may be a mechanism to facilitate lipolysis by increasing the surface-to-volume ratio, but microsized $\mathrm{LD}$ formation has not been shown to correlate closely to release of lipolytic products (Bickel et al. 2009), and seem to be generated in a region distant from the original LD (Yamaguchi et al. 2007; Nagayama et al. 2010). Additionally, the origin of the mechanical force needed to fragment a viscous lipid ester mass is not evident. The possibility that microsized LDs were made by reesterification of lipolytic products rather than by fragmentation of large LDs cannot be excluded.

Cell death-inducing DNA fragmentation factor-45-like effector (Cide) proteins, i.e., Cidea, Cideb, and fat-specific protein 27 (Fsp27 also known as Cidec in humans), play important roles in lipid metabolism and are at least partially distributed in LDs (Gong et al. 2009). Mice deficient in Cidea, Cideb, or Fsp27 show high-energy consumption, are resistant to high fat diet-induced obesity, and show a decrease of LDs in white adipocytes. In addition, Fsp27 deletion caused transformation of the large unilocular LD into small multilocular LDs (Nishino et al. 2008). Although lipolysis was induced similarly when either Fsp27 or perilipin was lacking, LD morphology changed significantly only when Fsp27 was deleted (Nishino et al. 2008), suggesting that Fsp27 influences lipid metabolism by changing the surface-tovolume ratio of LDs.

\section{GENERAL LIPID DROPLET FUNCTIONS}

\section{Storage of Lipid Esters}

LDs in nonadipocytes also store lipids, but the function of PAT proteins is less understood than in adipocytes. Overexpression of ADRP increases lipid ester storage in LDs, and this effect is thought to occur by limiting ATGL access to the esters (Listenberger et al. 2007). TIP47 appears to substitute the function of ADRP at least partially, and when both ADRP and TIP47 are deficient, incorporated fatty acids are used to make phospholipids rather than TG (Sztalryd et al. 2006). OXPAT/MLDP/ LSDP5 enhances lipid storage by curbing lipolysis (Dalen et al. 2007) and it also increases $\beta$-oxidation by recruiting CGI-58 to LDs and thereby enhancing the ATGL activity (Granneman et al. 2009). Microsomal TG content is increased or decreased by deletion or overexpression of ADRP, respectively, suggesting that ADRP promotes LD formation at the expense of microsomal storage (Chang et al. 2006; Listenberger et al. 2007). This result suggests that ADRP not only protects lipid esters from lipases, but it is also intimately related to the process of $\mathrm{LD}$ formation. It is intriguing that the ER membrane proteins FIT1 and FIT2 also appear to facilitate LD formation without enhancing TG synthesis or inhibiting lipolysis (Kadereit et al. 2008). PAT proteins, as well as FIT1 and FIT2, are likely to constitute an active molecular mechanism making LDs from lipid ester in the membrane.

Synthesis of lipid esters is not only for later lipid utilization but also an important defense mechanism against lipotoxicity (Schaffer 2003). Unsaturated fatty acids help cells to circumvent the toxicity of saturated fatty acid in mammalian cells by promoting TG production (Listenberger et al. 2003). This function is also important in cardiomyocytes that are exposed to ischemia and reperfusion (Barba et al. 2009), neurons during nutrient deprivation ( Du et al. 
2009), and cells under various stresses (Gubern et al. 2009). In Saccharomyces cerevisiae, a mutant lacking all lipid ester synthesis is viable under the normal conditions (Sandager et al. 2002), but excess unsaturated fatty acids causes massive membrane proliferation and cell death (Petschnigg et al. 2009). This result suggests that lipid ester synthesis is critical for proper handling of fatty acids and maintaining membrane homeostasis in the cell.

Additionally, production of CE directly regulates FC content of the ER membrane and the nuclear envelope. Elevation of the FC content in the membrane may lead to an increase in membrane order, which then decreases the conformational freedom of membrane proteins and disrupts seemingly unrelated functions such as nuclear pore complex formation ( $\mathrm{Li}$ et al. 2004; Hodge et al. 2010).

\section{Utilization of Stored Lipids}

In nonadipocytes, ATGL is likely to mediate most of the lipolytic activity even in the presence of HSL. ATGL homologs are also expressed in nonmammalian organisms and the phenotypes that arise from their manipulation shows the physiological importance of this enzyme and lipid storage in LDs. In S. cerevisiae, the ATGL homolog Tgl4 localizes almost exclusively in LDs and is activated through phosphorylation by the cyclin-dependent kinase (Kurat et al. 2009). Deletion of Tgl4 along with another lipase, Tgl3, caused a delay in cell-cycle entry by membrane deficiency and a resultant defect in secretion (Kurat et al. 2009). In Drosophila melanogaster, loss of the ATGL ortholog, or Brummer lipase, induced lethality in embryos (Gronke et al. 2005). Because these mutant cells retain de novo fatty acid synthetic pathways and may also take up fatty acids from exogenous sources, the results suggest that fatty acids liberated by hydrolysis of LD-stored lipid esters may be used for some critical pathways more efficiently than those from other sources. It is also possible that other metabolites are produced simultaneously, such as diacylglycerol and monoacylglycerol, play pivotal signaling roles. A similar preference for LD-derived lipids was also shown for very low-density lipoprotein (VLDL) production in hepatocytes (Gibbons et al. 2000), for efficient phagocytosis in macrophages (Chandak et al. 2010), and for arylceramide synthesis in keratinocytes (Gruber et al. 2010).

Another hydrolyzing enzyme, triglyceride hydrolase (TGH), has been shown to be crucial for VLDL synthesis in liver (Gilham et al. 2004). Notably, TGH is a soluble ER luminal protein, and how TGH functions to mobilize lipids in LDs is enigmatic. Very recently, TGH was shown to facilitate incorporation of newly synthesized TG to existing LDs, but the mechanism behind this phenomenon or its relationship to VLDL synthesis is not known (Wang et al. 2010).

In addition to cytosolic lipases, macroautophagy of LDs was shown to participate in lipid ester metabolism (Singh et al. 2009). The process was termed lipophagy, and cells deficient in this process accumulated excessive LDs. In autophagosome formation, proteolytic processing of soluble protein LC3-I and its conjugation to PE are indispensable. Surprisingly, LC3-I was found constitutively in LDs, and autophagosomes appeared to form in and around LDs (Singh et al. 2009). This result suggested that LDs are not just a client of target-specific autophagy like mitophagy and pexophagy (Ishihara et al. 2009), but may play an essential role in the autophagic process. However, another group reported that autophagy-deficient cells have scarce LDs and concluded that LC3-II is crucial for LD formation (Shibata et al. 2009). The effects of autophagy deficiency on LDs as reported in the two papers are contradictory, and it is not clear how they can be reconciled. It also remains to be clarified whether lipids processed by lipophagy have any functional preference that is different from those obtained by hydrolysis by cytosolic lipases.

\section{Lipid Synthesis and Metabolism}

Enzymes involved in various lipid metabolic pathways including fatty acid and steroid synthesis and fatty acid activation are recovered in LD and membrane fraction (Goodman 2009). Combined with other studies, this result suggests 
that some metabolic reactions occur in LDs, but many of those enzyme molecules are thought to be multispanning membrane proteins and are not likely to reside in the phospholipid monolayer of the LD surface. A simple assumption is that the enzymes are in the ER membrane adjacent to LDs and are recovered in the LD fraction as contaminants. However, the activity of some enzymes is different depending on the existing fraction (Goodman 2009), suggesting that the dichotomous partitioning has physiological relevance. It is possible, for example, that the ER membrane is separated into the lipid ester-poor and -rich domains, and that the latter is recovered in the LD fraction because of its relatively high buoyancy.

The presence of several enzymes for eicosanoid synthesis in LDs has been shown in leukocytes (Bozza et al. 2009). An endocannabinoid monoacylglycerol, 2-arachidonoylglycerol, may also be synthesized from TG in LDs by the action of ATGL and HSL (Zechner et al. 2009). More recently, one of the two fatty acid amide hydrolases, which hydrolyze N-acylethanolamines, was shown to reside in LDs (Kaczocha et al. 2010). These results indicate that LDs are a site in which signaling lipids are formed and metabolized.

\section{Nonconventional Functions}

Apart from the canonical functions, LDs appear to be involved in other phenomena that are not directly related to lipid storage or metabolism. In hepatocytes, lipidated apolipoprotein B-100 (ApoB) accumulates in LDs when either the proteasome or autophagy is inhibited (Ohsaki et al. 2006, 2008). The retention of $A$ poB on LDs is favorable for the cell because hydrophobic proteins like ApoB may form aggregates when left free in the aqueous milieu. Another hydrophobic protein, $\alpha$-synuclein, is degraded by the proteasome and autophagy, and also shows a prominent accumulation in LDs (Cole et al. 2002; Webb et al. 2003). We speculate that LDs may function as a temporal storage site for hydrophobic proteins and serve as a platform for their degradation (Fujimoto et al. 2006). It is not known, however, how the large mass of lipidated ApoB can egress from the ER lumen to the cytoplasm in which degradation machinery exists, but LDs may be also involved in the retrotranslocation process (Ploegh 2007).

Proteins that are not destined for degradation may also reside in LDs under some circumstances (Welte 2007). Histones are sequestered in the LD of the Drosophila embryo at one stage, and are then released to enter the nucleus later in development (Cermelli et al. 2006). In contrast to ApoB and $\alpha$-synuclein, which bind to LDs by hydrophobic interaction with lipid esters, the binding of histone may be electrostatic and lipid esters may not be involved in the interaction. This raises the question of why LDs are used for such sequestration because the number of LDs, and thus available surface area, may fluctuate widely depending on the cellular lipid content. Conventional membranes would appear to provide a greater surface area than LDs that invariably take a spherical shape. The molecular mechanisms that regulate LD binding of proteins should illuminate why LDs are used for such seemingly remote purposes.

\section{LIPID DROPLETS IN THE CELLULAR CONTEXT}

\section{Interactions with Other Organelles}

Lipid droplets are often associated with other organelles in the cell (Fig. 3A) (Fujimoto et al. 2008; Murphy et al. 2009). The association with the ER may occur because the ER is the site of $\mathrm{LD}$ formation, but closer apposition is formed when Rab18 is overexpressed or ADRP is decreased (Ozeki et al. 2005). Because the ER is suggested to function as a conduit for intracellular lipid trafficking, LD-ER interaction may represent a mechanism by which lipids stored in LDs are mobilized for use in other cellular sites (Levine 2004). LDs are also in close proximity to mitochondria and peroxisomes, in which fatty acids liberated by lipolysis are used for $\beta$-oxidation. LDs and the associated organelles may form close membrane contacts as shown by Förster Resonance Energy Transfer (FRET) (Sturmey et al. 2006). In S. cerevisiae 
cultured with oleic acid, LDs are stably coupled with peroxisomes making a hemi-fusion structure (Binns et al. 2006).

In addition to the above associations, LDs make a kiss-and-run type contact with phagosomes (van Manen et al. 2005). This transient encounter in neutrophils was speculated to supply phagosomes with arachidonic acid for NADPH oxidase activation. A recent study showed that the LD-phagosome association in dendritic cells may be related to cross-presentation (Bougneres et al. 2009), in which peptides processed in phagosomes are transported to the ER lumen, and loaded on MHC class I molecules. Both knockdown of Irgm3, an LDresident GTPase that binds to ADRP, and inhibition of DGAT separately impaired crosspresentation of phagocytosed antigens to CD8 (+) T lymphocytes (Bougneres et al. 2009). Dissection of the molecular mechanism of transient contact is important to understand its functional significance.

Several studies show that down-regulation of the ARF1-COPI pathway induces LD enlargement (Beller et al. 2008; Guo et al. 2008; Soni et al. 2009). It was conjectured that the ARF1-COPI pathway might increase lipolysis at LDs by modulating PAT protein composition in LDs and/or targeting ATGL to LDs. More recently, ARF-related protein 1 (ARFRP1) deficiency in brown adipocytes was shown to decrease SNAP23 and increase ATGL in LDs, thereby causing defective LD growth (Hommel et al. 2010). It is not likely, however, that vesicular transports are necessary for LD targeting of ATGL and PAT proteins. In one study, the disruption of the SAR1-COPII pathway in S. cerevisiae was also shown to give a similar result (Soni et al. 2009); a defect in the secretory pathway at the plasma membrane as well as Sec13 mutation enlarged LDs by decreasing phospholipids and increasing TG synthesis (Gaspar et al. 2008). This suggests that the observed change in LDs may not be a direct consequence of aberrant vesicular trafficking. The effects of ARF1 and ARFRP1 on LDs may be mediated by direct binding of ARF1 and ADRP and the concomitant modification of ADRP functions (Nakamura et al. 2004).
Interactions with Caveolae, Caveolins, and Cavins

Caveolins are integral membrane proteins that form the framework of caveolae by making high molecular weight oligomers. Caveolins associate with LDs in fatty acid-loaded cultured cells (Pol et al. 2005) and in regenerating hepatocytes in vivo (Fernandez et al. 2006). In 3T3-L1 adipocytes, cholesterol addition induces budding of caveolae and caveolin-1 transport to LDs (Le Lay et al. 2006). How caveolin-1 is translocated to LDs is not known, but hemi-fusion between the vesicular membrane and LDs is a possible mechanism (Murphy et al. 2009). Intriguingly, caveolae in adipocytes were suggested to produce TG (Ost et al. 2005), which may also be transferred to LDs through the hemi-fusion channel. The functions of caveolins are closely linked to a family of cytoplasmic proteins termed cavins (Hill et al. 2008; Bastiani et al. 2009; Hansen et al. 2009; McMahon et al. 2009). PTRF/ cavin-1 is essential for the formation of caveolae (Hill et al. 2008; Liu et al. 2008) and, like caveolin, has been shown to be associated with LD function and lipid storage in cultured adipocytes (Aboulaich et al. 2006), mice (Liu et al. 2008), and human patients (Hayashi et al. 2009; Rajab et al. 2010).

\section{Lipid Droplet Motility}

The motility of LDs is important to regulate their intracellular distribution and interactions with other organelles. LDs show both random short-distance and microtubule-based directional long-distance movements (Welte 2009). Dynein (Gross et al. 2000; Bostrom et al. 2005) and kinesin-1 (Shubeita et al. 2008) (minusend and plus-end motors, respectively) were found to associate with LDs. In Drosophila melanogaster, a PAT protein homolog, LSD2, regulates bidirectional LD movement by coordinating opposite-polarity motor proteins (Welte et al. 2005). Overexpression and deficiency of LSD2 leads to obese and lean flies, respectively, indicating that LSD2 is required for normal lipid storage (Gronke et al. 2003). 
This result suggests an intriguing possibility that LD motility and lipid metabolism is functionally integrated through LSD2. It is possible that active movement along microtubules increases the chance of mutual fusion, thereby promoting the formation of larger LDs, which are presumably more resistant to lipolysis than smaller LDs.

\section{LIPID DROPLETS AND DISEASE}

\section{Diseases Related to Lipid Storage}

Perilipin expression is an important factor associated with obesity (Tai et al. 2007). Curiously the effect is more robust in females than in males, in both humans and mice (Qi et al. 2004; Miyoshi et al. 2010), but the reason for the gender difference is not known. It is also noteworthy that not only perilipin-null mice but also perilipin transgenic mice are resistant to diet-induced obesity (Qi et al. 2004; Miyoshi et al. 2010). These results reflect the multifaceted nature of perilipin function and suggest that obesity is a systemic disease caused by a combination of environmental and genetic factors.

Neutral lipid storage disease (NLSD) is characterized by TG accumulation in multiple tissues (Schweiger et al. 2009). Loss-of-function mutations of CGI-58 cause NLSD with icthyosis, also called Chanarin-Dorfman syndrome, whereas ATGL mutations cause NLSD with myopathy (Fischer et al. 2007). Abnormal lipid storage can be explained by the decrease of ATGL activity, although NLSD patients are not obese (Igal et al. 1997). This contrasts with the obese phenotype of ATGL-null mice (Haemmerle et al. 2006), which implies that ATGL is less critical in human adipose tissue than in mouse tissue.

Lipodystrophies are disorders characterized by the loss of adipose tissue. Genetic mutation of LD-related proteins such as, seipin (Magre et al. 2001), caveolin-1 (Kim et al. 2008), PTRF/cavin1 (Hayashi et al. 2009; Rajab et al. 2010), and 1-acylglycerol-3-phosphate-O-acyltransferase 2 (Agarwal et al. 2002), which is a critical enzyme in TG and phospholipid synthesis, has been shown to cause lipodystrophies. The mechanism that seipin mutation leads to lipodystrophy may not be directly related to its effect on LD formation because it also affects a transcriptional cascade that drives adipogenesis (Payne et al. 2008; Chen et al. 2009).

\section{Motor Neuron Diseases}

Mutation of several LD proteins is linked to motor neuron diseases. One such protein is Spartin/SPG20. Spartin/SPG20 is an LD protein that binds to TIP47 (Eastman et al. 2009). Both Spartin/SPG20 and TIP47 compete with ADRP for LD association, and either knockdown or overexpression of Spartin/SPG20 leads to an increase in the number and size of LDs. A Spartin/SPG20 mutant that cannot compete with ADRP causes a motor neuron disease called Troyer syndrome (Patel et al. 2002). In normal cells, an E3 ligase, WWP1, appears to regulate the amount of Spartin/SPG20 and thereby adjust lipolysis by changing the TIP47to-ADRP ratio (Eastman et al. 2009; see Hooper et al. 2010 for an alternative view). Thus, the defect in Troyer syndrome is assumed to be aberrant turnover of LD lipids.

In contrast to the diseases that are explicitly related to LDs, motor neuron diseases appear to be quite remote from LD functionality, especially considering that LDs are not abundantly present in neurons. In fact, Troyer syndrome patients do not show obvious defects in general lipid metabolism. This tissue specificity may arise because motor neurons are especially susceptible to abnormal lipid turnover because of their long, myelinated axons. A similar neurological symptom is observed in the mutation or organophosphorus-induced inhibition of neuropathy target esterase (Rainier et al. 2008). This result also highlights that lipids stored in LDs are used for some specialized functions much more efficiently then lipids derived from other sources.

Loss-of-function mutations of seipin lead to lipodystrophy, whereas gain-of-toxic-function mutations of seipin cause motor neuron diseases, such as Silver syndrome/spastic paraplegia 17 and distal hereditary motor neuropathy 
type V (Windpassinger et al. 2004). The latter diseases are thought to be conformational diseases that are caused by accumulation of misfolded proteins in the ER and are not directly related to LD function (Ito et al. 2009).

\section{Infectious Agents}

Several pathogens take advantage of LDs for their proliferation and survival. Chlamydia trichomatis is an obligate intracellular pathogen that replicates in the vacuole called "inclusion" and uses host-derived lipids for its growth. Chlamydia secretes a protein, Lda3, that binds to LDs (Kumar et al. 2006) and causes their translocation from the cytoplasm to the inclusion lumen (Cocchiaro et al. 2008). Lda3 was found to dissociate ADRP from LDs, but the mechanism of LD translocation across the membrane remains enigmatic.

Hepatitis C virus (HCV) exploits LDs for proliferation in several different ways (Miyanari et al. 2007; McLauchlan 2009). First, a capsid Core protein and a noncapsid NS5A protein are both targeted to LDs (Barba et al. 1997; Shi et al. 2002) and the interaction between the two proteins is important for recruiting the replication complex to the vicinity of LDs (McLauchlan 2009). Second, Core induces LD aggregation near the microtubule-organizing center in a microtubule-dependent manner, in which redistribution is thought to play an important role for efficient virus production (Boulant et al. 2008). Third, HCV uses the lipoprotein synthesis pathway for its own assembly and secretion as a lipoviroparticle (Syed et al. 2010). All of these processes may disturb cellular lipid metabolism and culminate in steatosis and other liver diseases. Dengue virus has also been shown to exploit LDs for particle formation (Samsa et al. 2009).

In response to $\mathrm{HCV}$ infection, cells produce an interferon-induced antiviral protein, viperin, which inhibits HCV replication (Helbig et al. 2005). Viperin is targeted to both LDs and the ER membrane via its amino-terminal amphipathic $\alpha$-helix (Hinson et al. 2009). The HCV NS5A protein also localizes to LDs by an amphipathic $\alpha$-helix. It is postulated that part of the antiviral function of viperin is mediated by sharing the LD localization mechanism with NS5A (Hinson et al. 2009).

\section{FUTURE CHALLENGES}

Many new proteins and phenomena concerning LDs have been uncovered during the past few years and we are beginning to understand the physiology and pathology of LDs in molecular terms. However, many mysteries remain in the field, specifically concerning how each LD function is placed in its unique structural context. This is in contrast to conventional vesicular organelles that can be regarded as having a common structure.

Questions about LD structure may be reiterated as follows: Membranes and proteins may be present in the LD core, but how do they exist in a highly hydrophobic environment? If the LD surface is covered by a phospholipid monolayer, how do lipases get access to lipid esters? Are lipid esters interspersed within the phospholipid monolayer, or do lipids make any other structure locally and/or temporarily so that lipid esters are exposed to the cytoplasm? LDs are supposed to meet with conventional vesicles and exchange materials, but do bilayer membranes fuse (or hemi-fuse) with the monolayer? Sophisticated model systems that mimic natural LDs may help resolve these questions in the way that artificial liposomes have performed for membrane studies (Small et al. 2009).

Functionally we would like to know why fatty acids generated in LDs are used more effectively than those from other sources in many reactions (Gibbons et al. 2000; Kurat et al. 2009; Chandak et al. 2010; Gruber et al. 2010). The difference may be attributed to other metabolites made in LDs and/or the dynamic hydrolysis-reacylation cycle in LDs. The ability to dispatch lipids to necessary locations may also be important. We should also examine whether simple physical competition at the LD surface, e.g., ADRP vs. ATGL, can explain various functional consequences.

Although we have progressed a long way from the image of the lipid droplet as an inert fat deposit, these questions clearly reveal how 
far we are from a complete understanding of this complex organelle. Future studies on the basic biological properties of LDs should help us understand many more diseases and provide new molecular targets for therapeutic intervention.

\section{ACKNOWLEDGMENTS}

Works in our laboratory have been supported by Grants-in-Aid for Scientific Research and the 21st Century COE Program "Integrated Molecular Medicine for Neuronal and Neoplastic Disorders" of the Ministry of Education, Culture, Sports, Science and Technology of the Government of Japan (to TF) and the National Health and Medical Research Council of Australia (to RGP). We are grateful to Michitaka Suzuki, Samantha Murphy, and Carol Kistler for comments on the manuscript.

\section{REFERENCES}

Aboulaich N, Ortegren U, Vener AV, Stralfors P. 2006. Association and insulin regulated translocation of hormonesensitive lipase with ptrf. Biochem Biophys Res Commun 350: 657-661.

Agarwal AK, Arioglu E, De Almeida S, Akkoc N, Taylor SI, Bowcock AM, Barnes RI, Garg A. 2002. Agpat2 is mutated in congenital generalized lipodystrophy linked to chromosome 9q34. Nat Genet 31: 21-23.

Austin JR II, Frost E, Vidi PA, Kessler F, Staehelin LA. 2006. Plastoglobules are lipoprotein subcompartments of the chloroplast that are permanently coupled to thylakoid membranes and contain biosynthetic enzymes. Plant Cell 18: 1693-1703.

Baba M, Osumi M, Ohsumi Y. 1995. Analysis of the membrane structures involved in autophagy in yeast by freeze-replica method. Cell Struct Funct 20: 465-471.

Barba I, Chavarria L, Ruiz-Meana M, Mirabet M, Agullo E, Garcia-Dorado D. 2009. Effect of intracellular lipid droplets on cytosolic $\mathrm{CA}^{2+}$ and cell death during ischaemiareperfusion injury in cardiomyocytes. J Physiol 587: 1331-1341.

Barba G, Harper F, Harada T, Kohara M, Goulinet S, Matsuura Y, Eder G, Schaff Z, Chapman MJ, Miyamura T, et al. 1997. Hepatitis c virus core protein shows a cytoplasmic localization and associates to cellular lipid storage droplets. Proc Natl Acad Sci 94: 1200-1205.

Bartz R, Li WH, Venables B, Zehmer JK, Roth MR, Welti R, Anderson RG, Liu P, Chapman KD. 2007. Lipidomics reveals that adiposomes store ether lipids and mediate phospholipid traffic. J Lipid Res 48: 837-847.

Bastiani M, Liu L, Hill MM, Jedrychowski MP, Nixon SJ, Lo HP, Abankwa D, Luetterforst R, Fernandez-Rojo M,
Breen MR, et al. 2009. Murc/cavin-4 and cavin family members form tissue-specific caveolar complexes. J Cell Biol 185: 1259-1273.

Beller M, Sztalryd C, Southall N, Bell M, Jackle H, Auld DS, Oliver B. 2008. Copi complex is a regulator of lipid homeostasis. PLoS Biol 6: e292.

Beller M, Thiel K, Thul PJ, Jackle H. 2010. Lipid droplets: A dynamic organelle moves into focus. FEBS Lett 584: 2176-2182.

Bickel PE, Tansey JT, Welte MA. 2009. Pat proteins, an ancient family of lipid droplet proteins that regulate cellular lipid stores. Biochim Biophys Acta 1791: 419-440.

Binns D, Januszewski T, Chen Y, Hill J, Markin VS, Zhao Y, Gilpin C, Chapman KD, Anderson RG, Goodman JM. 2006. An intimate collaboration between peroxisomes and lipid bodies. J Cell Biol 173: 719-731.

Blanchette-Mackie EJ, Dwyer NK, Barber T, Coxey RA, Takeda T, Rondinone CM, Theodorakis JL, Greenberg AS, Londos C. 1995. Perilipin is located on the surface layer of intracellular lipid droplets in adipocytes. J Lipid Res 36: 1211-1226.

Bostrom P, Andersson L, Rutberg M, Perman J, Lidberg U, Johansson BR, Fernandez-Rodriguez J, Ericson J, Nilsson T, Boren J, et al. 2007. Snare proteins mediate fusion between cytosolic lipid droplets and are implicated in insulin sensitivity. Nat Cell Biol 9: 1286-1293.

Bostrom P, Rutberg M, Ericsson J, Holmdahl P, Andersson L, Frohman MA, Boren J, Olofsson SO. 2005. Cytosolic lipid droplets increase in size by microtubule-dependent complex formation. Arterioscler Thromb Vasc Biol 25: 1945-1951.

Bougneres L, Helft J, Tiwari S, Vargas P, Chang BH, Chan L, Campisi L, Lauvau G, Hugues S, Kumar P, et al. 2009. A role for lipid bodies in the cross-presentation of phagocytosed antigens by mhc class $\mathrm{i}$ in dendritic cells. Immunity 31: $232-244$.

Boulant S, Douglas MW, Moody L, Budkowska A, Targett-Adams P, McLauchlan J. 2008. Hepatitis c virus core protein induces lipid droplet redistribution in a microtubule- and dynein-dependent manner. Traffic 9: $1268-1282$.

Bozza PT, Magalhaes KG, Weller PF. 2009. Leukocyte lipid bodies-biogenesis and functions in inflammation. Biochim Biophys Acta 1791: 540-551.

Bozza PT, Yu W, Penrose JF, Morgan ES, Dvorak AM, Weller PF. 1997. Eosinophil lipid bodies: Specific, inducible intracellular sites for enhanced eicosanoid formation. J Exp Med 186: 909-920.

Brasaemle DL. 2007. Thematic review series: Adipocyte biology. The perilipin family of structural lipid droplet proteins: Stabilization of lipid droplets and control of lipolysis. J Lipid Res 48: 2547-2559.

Bulankina A, Deggerich A, Wenzel D, Mutenda K, Wittmann J, Rudolph M, Burger K, Honing S. 2009. Tip47 functions in the biogenesis of lipid droplets. J Cell Biol 185: 641-655.

Cermelli S, Guo Y, Gross SP, Welte MA. 2006. The lipiddroplet proteome reveals that droplets are a proteinstorage depot. Curr Biol 16: 1783-1795.

Chandak PG, Radovic B, Aflaki E, Kolb D, Buchebner M, Froehlich E, Magnes C, Sinner F, Haemmerle G, Zechner 
R, et al. 2010. Efficient phagocytosis requires triacylglycerol hydrolysis by adipose triglyceride lipase. J Biol Chem 285: 20192-20201.

Chang BH, Li L, Paul A, Taniguchi S, Nannegari V, Heird WC, Chan L. 2006. Protection against fatty liver but normal adipogenesis in mice lacking adipose differentiationrelated protein. Mol Cell Biol 26: 1063-1076.

Chang TY, Li BL, Chang CC, Urano Y. 2009. Acyl-coenzyme a: Cholesterol acyltransferases. Am J Physiol Endocrinol Metab 297: E1-9.

Cheng J, Fujita A, Ohsaki Y, Suzuki M, Shinohara Y, Fujimoto T. 2009. Quantitative electron microscopy shows uniform incorporation of triglycerides into existing lipid droplets. Histochem Cell Biol 132: 281-291.

Chen W, Yechoor VK, Chang BH, Li MV, March KL, Chan L. 2009. The human lipodystrophy gene product berardinelli-seip congenital lipodystrophy 2 /seipin plays a key role in adipocyte differentiation. Endocrinology 150: $4552-4561$.

Cocchiaro JL, Kumar Y, Fischer ER, Hackstadt T, Valdivia RH. 2008. Cytoplasmic lipid droplets are translocated into the lumen of the Chlamydia trachomatis parasitophorous vacuole. Proc Natl Acad Sci 105: 9379-9384.

Cole NB, Murphy DD, Grider T, Rueter S, Brasaemle D, Nussbaum RL. 2002. Lipid droplet binding and oligomerization properties of the Parkinson's disease protein $\alpha$-synuclein. J Biol Chem 277: 6344-6352.

Czabany T, Wagner A, Zweytick D, Lohner K, Leitner E, Ingolic E, Daum G. 2008. Structural and biochemical properties of lipid particles from the yeast Saccharomyces cerevisiae. J Biol Chem 283: 17065-17074.

Dalen KT, Dahl T, Holter E, Arntsen B, Londos C, Sztalryd C, Nebb HI., 2007. Lsdp5 is a pat protein specifically expressed in fatty acid oxidizing tissues. Biochim Biophys Acta 1771: 210-227.

Du L, Hickey RW, Bayir H, Watkins SC, Tyurin VA, Guo F, Kochanek PM, Jenkins LW, Ren J, Gibson G, et al. 2009. Starving neurons show sex difference in autophagy. J Biol Chem 284: 2383-2396.

Ducharme NA, Bickel PE. 2008. Lipid droplets in lipogenesis and lipolysis. Endocrinology 149: 942-949.

Dvorak AM, Morgan E, Schleimer RP, Ryeom SW, Lichtenstein LM, Weller PF. 1992. Ultrastructural immunogold localization of prostaglandin endoperoxide synthase (cyclooxygenase) to non-membrane-bound cytoplasmic lipid bodies in human lung mast cells, alveolar macrophages, type ii pneumocytes, and neutrophils. J Histochem Cytochem 40: 759-769.

Eastman SW, Yassaee M, Bieniasz PD. 2009. A role for ubiquitin ligases and spartin/spg20 in lipid droplet turnover. J Cell Biol 184: 881-894.

Fei W, Shui G, Gaeta B, Du X, Kuerschner L, Li P, Brown AJ, Wenk MR, Parton RG, Yang H. 2008. Fld1p, a functional homologue of human seipin, regulates the size of lipid droplets in yeast. J Cell Biol 180: 473-482.

Fernandez MA, Albor C, Ingelmo-Torres M, Nixon SJ, Ferguson C, Kurzchalia T, Tebar F, Enrich C, Parton RG, Pol A. 2006. Caveolin-1 is essential for liver regeneration. Science 313: $1628-1632$.

Fischer J, Lefevre C, Morava E, Mussini JM, Laforet P, NegreSalvayre A, Lathrop M, Salvayre R. 2007. The gene encoding adipose triglyceride lipase (pnpla2) is mutated in neutral lipid storage disease with myopathy. Nat Genet 39: $28-30$.

Fujimoto T, Ohsaki Y. 2006. Cytoplasmic lipid droplets: Rediscovery of an old structure as a unique platform. Ann N Y Acad Sci 1086: 104-115.

Fujimoto T, Ohsaki Y, Cheng J, Suzuki M, Shinohara Y. 2008. Lipid droplets: A classic organelle with new outfits. Histochem Cell Biol 130: 263-279.

Gaspar ML, Jesch SA, Viswanatha R, Antosh AL, Brown WJ, Kohlwein SD, Henry SA. 2008. A block in endoplasmic reticulum-to-golgi trafficking inhibits phospholipid synthesis and induces neutral lipid accumulation. J Biol Chem 283: 25735-25751.

Gibbons GF, Islam K, Pease RJ. 2000. Mobilisation of triacylglycerol stores. Biochim Biophys Acta 1483: 37-57.

Gilham D, Lehner R. 2004. The physiological role of triacylglycerol hydrolase in lipid metabolism. Rev Endocr Metab Disord 5: 303-309.

Gong J, Sun Z, Li P. 2009. Cide proteins and metabolic disorders. Curr Opin Lipidol 20: 121-126.

Goodman JM. 2008. The gregarious lipid droplet. J Biol Chem 283: 28005-28009.

Goodman JM. 2009. Demonstrated and inferred metabolism associated with cytosolic lipid droplets. J Lipid Res 50: $2148-2156$.

Granneman JG, Moore HP, Granneman RL, Greenberg AS, Obin MS, Zhu Z. 2007. Analysis of lipolytic protein trafficking and interactions in adipocytes. J Biol Chem 282: 5726-5735.

Granneman JG, Moore HP, Mottillo EP, Zhu Z. 2009. Functional interactions between mldp (lsdp5) and abhd5 in the control of intracellular lipid accumulation. J Biol Chem 284: 3049-3057.

Greenberg AS, Egan JJ, Wek SA, Garty NB, BlanchetteMackie EJ, Londos C. 1991. Perilipin, a major hormonally regulated adipocyte-specific phosphoprotein associated with the periphery of lipid storage droplets. J Biol Chem 266: 11341-11346.

Gronke S, Beller M, Fellert S, Ramakrishnan H, Jackle H, Kuhnlein RP. 2003. Control of fat storage by a Drosophila pat domain protein. Curr Biol 13: 603-606.

Gronke S, Mildner A, Fellert S, Tennagels N, Petry S, Muller G, Jackle H, Kuhnlein RP. 2005. Brummer lipase is an evolutionary conserved fat storage regulator in Drosophila. Cell Metab 1: 323-330.

Gross SP, Welte MA, Block SM, Wieschaus EF. 2000. Dyneinmediated cargo transport in vivo. A switch controls travel distance. J Cell Biol 148: 945-956.

Gruber A, Cornaciu I, Lass A, Schweiger M, Poeschl M, Eder C, Kumari M, Schoiswohl G, Wolinski H, Kohlwein SD, et al. 2010. The $\mathrm{N}$-terminal region of comparative gene identification-58 (cgi-58) is important for lipid droplet binding and activation of adipose triglyceride lipase. J Biol Chem 285: 12289-12298.

Gubern A, Barcelo-Torns M, Casas J, Barneda D, Masgrau R, Picatoste F, Balsinde J, Balboa MA, Claro E. 2009. Lipid droplet biogenesis induced by stress involves triacylglycerol synthesis that depends on group via phospholipase a2. J Biol Chem 284: 5697-5708. 
Gubern A, Casas J, Barcelo-Torns M, Barneda D, de la Rosa X, Masgrau R, Picatoste F, Balsinde J, Balboa MA, Claro E. 2008. Group iva phospholipase a2 is necessary for the biogenesis of lipid droplets. J Biol Chem 283: 27369 27382.

Guo Y, Walther TC, Rao M, Stuurman N, Goshima G, Terayama K, Wong JS, Vale RD, Walter P, Farese RV. 2008. Functional genomic screen reveals genes involved in lipid-droplet formation and utilization. Nature 453: 657-661.

Haemmerle G, Lass A, Zimmermann R, Gorkiewicz G, Meyer C, Rozman J, Heldmaier G, Maier R, Theussl C, Eder S, et al. 2006. Defective lipolysis and altered energy metabolism in mice lacking adipose triglyceride lipase. Science 312: 734-737.

Hakumaki JM, Kauppinen RA. 2000. 1h nmr visible lipids in the life and death of cells. Trends Biochem Sci 25: $357-362$.

Hamilton JA. 1989. Interactions of triglycerides with phospholipids: Incorporation into the bilayer structure and formation of emulsions. Biochemistry 28: 2514-2520.

Hamilton JA, Small DM. 1982. Solubilization and localization of cholesteryl oleate in egg phosphatidylcholine vesicles. A carbon $13 \mathrm{nmr}$ study. J Biol Chem 257: 7318-7321.

Hansen CG, Bright NA, Howard G, Nichols BJ. 2009. Sdpr induces membrane curvature and functions in the formation of caveolae. Nat Cell Biol 11: 807-814.

Hayashi YK, Matsuda C, Ogawa M, Goto K, Tominaga K, Mitsuhashi S, Park YE, Nonaka I, Hino-Fukuyo N, Haginoya K, et al. 2009. Human ptrf mutations cause secondary deficiency of caveolins resulting in muscular dystrophy with generalized lipodystrophy. J Clin Invest 119: 2623-2633.

Helbig KJ, Lau DT, Semendric L, Harley HA, Beard MR 2005. Analysis of isg expression in chronic hepatitis c identifies viperin as a potential antiviral effector. Нераtology 42: 702-710.

Hevonoja T, Pentikainen MO, Hyvonen MT, Kovanen PT Ala-Korpela M. 2000. Structure of low density lipoprotein (ldl) particles: Basis for understanding molecular changes in modified ldl. Biochim Biophys Acta 1488: $189-210$.

Hill MM, Bastiani M, Luetterforst R, Kirkham M, Kirkham A, Nixon SJ, Walser P, Abankwa D, Oorschot VM, Martin S, et al. 2008. Ptrf-cavin, a conserved cytoplasmic protein required for caveola formation and function. Cell 132: $113-124$.

Hinson ER, Cresswell P. 2009. The antiviral protein, viperin, localizes to lipid droplets via its n-terminal amphipathic

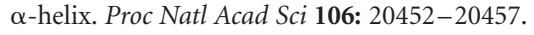

Hodge CA, Choudhary V, Wolyniak MJ, Scarcelli JJ, Schneiter R, Col CN. 2010. Integral membrane proteins brr6 and apq12 link assembly of the nuclear pore complex to lipid homeostasis in the endoplasmic reticulum. J Cell Sci 123: 141-151.

Hodges BD, Wu CC. 2009. Proteomic insights into an expanded cellular role for cytoplasmic lipid droplets. J Lipid Res 51: 262-273.

Hommel A, Hesse D, Volker W, Jaschke A, Moser M, Engel T, Bluher M, Zahn C, Chadt A, Ruschke K, et al. 2010. The arf-like gtpase arfrp1 is essential for lipid droplet growth and is involved in the regulation of lipolysis. Mol Cell Biol 30: $1231-1242$.

Hooper C, Puttamadappa SS, Loring Z, Shekhtman A, Bakowska JC. 2010. Spartin activates atrophin-1-interacting protein 4 (aip4) e3 ubiquitin ligase and promotes ubiquitination of adipophilin on lipid droplets. $B M C$ Biol 8: 72.

Igal RA, Rhoads JM, Coleman RA. 1997. Neutral lipid storage disease with fatty liver and cholestasis. J Pediatr Gastroenterol Nutr 25: 541-547.

Ishihara N, Mizushima N. 2009. A receptor for eating mitochondria. Dev Cell 17: 1-2.

Ito D, Suzuki N. 2009. Seipinopathy: A novel endoplasmic reticulum stress-associated disease. Brain 132: 8-15.

Jacobs RL, Lingrell S, Zhao Y, Francis GA, Vance DE. 2008. Hepatic ctp:Phosphocholine cytidylyltransferase- $\alpha$ is a critical predictor of plasma high density lipoprotein and very low density lipoprotein. J Biol Chem 283: 2147 2155.

Kaczocha M, Glaser S, Chae J, Brown D, Deutsch D. 2010. Lipid droplets are novel sites of $\mathrm{n}$-acylethanolamine inactivation by fatty acid amide hydrolase-2.J Biol Chem 285: 2796-2806.

Kadereit B, Kumar P, Wang WJ, Miranda D, Snapp EL, Severina N, Torregroza I, Evans T, Silver DL. 2008. Evolutionarily conserved gene family important for fat storage. Proc Natl Acad Sci 105: 94-99.

Kaye GWC, Laby TH. 1995. Tables of physical and chemical compounds, 16th ed. Longman Scientic and Technical, Essex, UK.

Kim CA, Delepine M, Boutet E, El Mourabit H, Le Lay S, Meier M, Nemani M, Bridel E, Leite CC, Bertola DR, et al. 2008. Association of a homozygous nonsense caveolin-1 mutation with Berardinelli-Seip congenital lipodystrophy. J Clin Endocrinol Metab 93: 1129-1134.

Kimmel AR, Brasaemle DL, McAndrews-Hill M, Sztalryd C, Londos C. 2010. Adoption of perilipin as a unifying nomenclature for the mammalian pat-family of intracellular lipid storage droplet proteins. J Lipid Res 51: $468-471$.

Kuerschner L, Moessinger C, Thiele C. 2008. Imaging of lipid biosynthesis: How a neutral lipid enters lipid droplets. Traffic 9: 338-352.

Kumar Y, Cocchiaro J, Valdivia RH. 2006. The obligate intracellular pathogen Chlamydia trachomatis targets host lipid droplets. Curr Biol 16: 1646-1651.

Kurat C, Wolinski H, Petschnigg J, Kaluarachchi S, Andrews B, Natter K, Kohlwein S. 2009. Cdk1/cdc28-dependent activation of the major triacylglycerol lipase tgl4 in yeast links lipolysis to cell-cycle progression. Mol Cell 33: 53-63.

Lass A, Zimmermann R, Haemmerle G, Riederer M, Schoiswohl G, Schweiger M, Kienesberger P, Strauss JG, Gorkiewicz G, Zechner R. 2006. Adipose triglyceride lipase-mediated lipolysis of cellular fat stores is activated by cgi-58 and defective in chanarin-dorfman syndrome. Cell Metab 3: 309-319.

Le Lay S, Hajduch E, Lindsay MR, Le Liepvre X, Thiele C, Ferre P, Parton RG, Kurzchalia T, Simons K, Dugail I. 2006. Cholesterol-induced caveolin targeting to lipid 
droplets in adipocytes: A role for caveolar endocytosis. Traffic 7: 549-561.

Leber R, Zinser E, Zellnig G, Paltauf F, Daum G. 1994. Characterization of lipid particles of the yeast, Saccharomyces cerevisiae. Yeast 10: 1421-1428.

Levine T. 2004. Short-range intracellular trafficking of small molecules across endoplasmic reticulum junctions. Trends Cell Biol 14: 483-490.

Li Y, Ge M, Ciani L, Kuriakose G, Westover EJ, Dura M, Covey DF, Freed JH, Maxfield FR, Lytton J, et al. 2004. Enrichment of endoplasmic reticulum with cholesterol inhibits sarcoplasmic-endoplasmic reticulum calcium atpase-2b activity in parallel with increased order of membrane lipids: Implications for depletion of endoplasmic reticulum calcium stores and apoptosis in cholesterol-loaded macrophages. J Biol Chem 279: 37030-37039.

Listenberger LL, Han X, Lewis SE, Cases S, Farese RVJr, Ory DS, Schaffer JE. 2003. Triglyceride accumulation protects against fatty acid-induced lipotoxicity. Proc Natl Acad Sci 100: 3077-3082.

Listenberger LL, Ostermeyer-Fay AG, Goldberg EB, Brown WJ, Brown DA. 2007. Adipocyte differentiation-related protein reduces the lipid droplet association of adipose triglyceride lipase and slows triacylglycerol turnover. J Lipid Res 48: 2751-2761.

Liu L, Brown D, McKee M, Lebrasseur NK, Yang D, Albrecht KH, Ravid K, Pilch PF. 2008. Deletion of cavin/ptrf causes global loss of caveolae, dyslipidemia, and glucose intolerance. Cell Metab 8: 310-317.

Londos C, Brasaemle DL, Schultz CJ, Segrest JP, Kimmel AR. 1999. Perilipins, adrp, and other proteins that associate with intracellular neutral lipid droplets in animal cells. Semin Cell Dev Biol 10: 51-58.

Magre J, Delepine M, Khallouf E, Gedde-Dahl TJr, Van Maldergem L, Sobel E, Papp J, Meier M, Megarbane A, Bachy A, et al. 2001. Identification of the gene altered in Berardinelli-Seip congenital lipodystrophy on chromosome 11q13. Nat Genet 28: 365-370.

Marchesan D, Rutberg M, Andersson L, Asp L, Larsson T, Boren J, Johansson BR, Olofsson SO. 2003. A phospholipase d-dependent process forms lipid droplets containing caveolin, adipocyte differentiation-related protein, and vimentin in a cell-free system. J Biol Chem 278: 27293-27300.

Marcinkiewicz A, Gauthier D, Garcia A, Brasaemle DL. 2006. The phosphorylation of serine 492 of perilipin a directs lipid droplet fragmentation and dispersion. $J$ Biol Chem 281: 11901-11909.

Martin S, Parton RG. 2006. Lipid droplets: A unified view of a dynamic organelle. Nat Rev Mol Cell Biol 7: 373-378.

McLauchlan J. 2009. Hepatitis c virus: Viral proteins on the move. Biochem Soc Trans 37: 986-990.

McMahon KA, Zajicek H, Li WP, Peyton MJ, Minna JD, Hernandez VJ, Luby-Phelps K, Anderson RG. 2009. $\mathrm{Srbc} / \mathrm{cavin}-3$ is a caveolin adapter protein that regulates caveolae function. EMBO J 28: 1001-1015.

Miyanari Y, Atsuzawa K, Usuda N, Watashi K, Hishiki T, Zayas M, Bartenschlager R, Wakita T, Hijikata M, Shimotohno K. 2007. The lipid droplet is an important organelle for hepatitis c virus production. Nat Cell Biol 9: 1089-1097.
Miyoshi H, Souza SC, Endo M, Sawada T, Perfield JWII, Shimizu C, Stancheva Z, Nagai S, Strissel KJ, Yoshioka $\mathrm{N}$, et al. 2010. Perilipin overexpression in mice protects against diet-induced obesity. J Lipid Res 51: 975-982.

Mountford CE, Wright LC. 1988. Organization of lipids in the plasma membranes of malignant and stimulated cells: A new model. Trends Biochem Sci 13: 172-177.

Murphy DJ. 2001. The biogenesis and functions of lipid bodies in animals, plants and microorganisms. Prog Lipid Res 40: 325-438.

Murphy DJ, Vance J. 1999. Mechanisms of lipid-body formation. Trends Biochem Sci 24: 109-115.

Murphy S, Martin S, Parton RG. 2009. Lipid droplet-organelle interactions; sharing the fats. Biochim Biophys Acta 1791: 441-447.

Nagayama M, Shimizu K, Taira T, Uchida T, Gohara K. 2010. Shrinking and development of lipid droplets in adipocytes during catecholamine-induced lipolysis. FEBS Lett 584: 86-92.

Nakamura N, Akashi T, Taneda T, Kogo H, Kikuchi A, Fujimoto T. 2004. Adrp is dissociated from lipid droplets by arf1-dependent mechanism. Biochem Biophys Res Commun 322: 957-965.

Nishino N, Tamori Y, Tateya S, Kawaguchi T, Shibakusa T, Mizunoya W, Inoue K, Kitazawa R, Kitazawa S, Matsuki Y, et al. 2008. Fsp27 contributes to efficient energy storage in murine white adipocytes by promoting the formation of unilocular lipid droplets. J Clin Invest 118: 2808-2821.

Novikoff AB, Novikoff PM, Rosen OM, Rubin CS. 1980. Organelle relationships in cultured 3t3-11 preadipocytes. J Cell Biol 87: 180-196.

Ohsaki Y, Cheng J, Fujita A, Tokumoto T, Fujimoto T. 2006. Cytoplasmic lipid droplets are sites of convergence of proteasomal and autophagic degradation of apolipoprotein b. Mol Biol Cell 17: 2674-2683.

Ohsaki Y, Cheng J, Suzuki M, Fujita A, Fujimoto T. 2008. Lipid droplets are arrested in the er membrane by tight binding of lipidated apolipoprotein b-100. J Cell Sci 121: $2415-2422$

Olofsson SO, Bostrom P, Andersson L, Rutberg M, Levin M, Perman J, Boren J. 2008. Triglyceride containing lipid droplets and lipid droplet-associated proteins. Curr Opin Lipidol 19: 441-447.

Ost A, Ortegren U, Gustavsson J, Nystrom FH, Stralfors P. 2005. Triacylglycerol is synthesized in a specific subclass of caveolae in primary adipocytes. J Biol Chem 280: 5-8.

Ozeki S, Cheng J, Tauchi-Sato K, Hatano N, Taniguchi H, Fujimoto T. 2005. Rab18 localizes to lipid droplets and induces their close apposition to the endoplasmic reticulum-derived membrane. J Cell Sci 118: 2601-2611.

Patel H, Cross H, Proukakis C, Hershberger R, Bork P, Ciccarelli FD, Patton MA, McKusick VA, Crosby AH. 2002. Spg20 is mutated in troyer syndrome, an hereditary spastic paraplegia. Nat Genet 31: 347-348.

Payne VA, Grimsey N, Tuthill A, Virtue S, Gray SL, Dalla Nora E, Semple RK, O’Rahilly S, Rochford JJ. 2008. The human lipodystrophy gene bscl2/seipin may be essential for normal adipocyte differentiation. Diabetes 57: 2055-2060.

Petschnigg J, Wolinski H, Kolb D, Zellnig G, Kurat CF, Natter K, Kohlwein SD. 2009. Good fat, essential cellular 
requirements for triacylglycerol synthesis to maintain membrane homeostasis in yeast. J Biol Chem 284: 30981-30993.

Ploegh HL. 2007. A lipid-based model for the creation of an escape hatch from the endoplasmic reticulum. Nature 448: $435-438$.

Pol A, Martin S, Fernandez MA, Ingelmo-Torres M, Ferguson C, Enrich C, Parton RG. 2005. Cholesterol and fatty acids regulate dynamic caveolin trafficking through the golgi complex and between the cell surface and lipid bodies. Mol Biol Cell 16: 2091-2105.

Prattes S, Horl G, Hammer A, Blaschitz A, Graier WF, Sattler W, Zechner R, Steyrer E. 2000. Intracellular distribution and mobilization of unesterified cholesterol in adipocytes: Triglyceride droplets are surrounded by cholesterol-rich er-like surface layer structures. J Cell Sci 113: 2977-2989.

Qi L, Shen H, Larson I, Schaefer EJ, Greenberg AS, Tregouet DA, Corella D, Ordovas JM. 2004. Gender-specific association of a perilipin gene haplotype with obesity risk in a white population. Obes Res 12: 1758-1765.

Rainier S, Bui M, Mark E, Thomas D, Tokarz D, Ming L, Delaney C, Richardson RJ, Albers JW, Matsunami N, et al. 2008. Neuropathy target esterase gene mutations cause motor neuron disease. Am J Hum Genet 82: 780 785.

Rajab A, Straub V, McCann LJ, Seelow D, Varon R, Barresi R, Schulze A, Lucke B, Lutzkendorf S, Karbasiyan M, et al. 2010. Fatal cardiac arrhythmia and long-qt syndrome in a new form of congenital generalized lipodystrophy with muscle rippling (cgl4) due to ptrf-cavin mutations. PLoS Genet 6: e1000874.

Robenek H, Robenek MJ, Troyer D. 2005. Pat family proteins pervade lipid droplet cores. J Lipid Res 46: 1331-1338.

Robenek MJ, Severs NJ, Schlattmann K, Plenz G, Zimmer KP, Troyer D, Robenek H. 2004. Lipids partition caveolin-1 from er membranes into lipid droplets: Updating the model of lipid droplet biogenesis. FASEB J 18: 866868.

Samsa MM, Mondotte JA, Iglesias NG, Assuncao-Miranda I, Barbosa-Lima G, Da Poian AT, Bozza PT, Gamarnik AV. 2009. Dengue virus capsid protein usurps lipid droplets for viral particle formation. PLoS Pathog 5: e1000632.

Sandager L, Gustavsson MH, Stahl U, Dahlqvist A, Wiber E, Banas A, Lenman M, Ronne H, Stymne S. 2002. Storage lipid synthesis is non-essential in yeast. J Biol Chem 277: 6478-6482.

Schaffer JE. 2003. Lipotoxicity: When tissues overeat. Curr Opin Lipidol 14: 281-287.

Schweiger M, Lass A, Zimmermann R, Eichmann TO, Zechner R. 2009. Neutral lipid storage disease: Genetic disorders caused by mutations in adipose triglyceride lipase/ pnpla2 or cgi-58/abhd5. Am J Physiol Endocrinol Metab 297: E289-E296.

Shi ST, Polyak SJ, Tu H, Taylor DR, Gretch DR, Lai MM 2002. Hepatitis c virus ns5a colocalizes with the core protein on lipid droplets and interacts with apolipoproteins. Virology 292: 198-210.

Shibata M, Yoshimura K, Furuya N, Koike M, Ueno T, Komatsu M, Arai H, Tanaka K, Kominami E, Uchiyama Y. 2009. The map1-lc3 conjugation system is involved in lipid droplet formation. Biochem Biophys Res Commun 382: $419-423$.

Shubeita GT, Tran SL, Xu J, Vershinin M, Cermelli S, Cotton SL, Welte MA, Gross SP. 2008. Consequences of motor copy number on the intracellular transport of kinesin1-driven lipid droplets. Cell 135: 1098-1107.

Singh R, Kaushik S, Wang Y, Xiang Y, Novak I, Komatsu M, Tanaka K, Cuervo AM, Czaja MJ. 2009. Autophagy regulates lipid metabolism. Nature 458: 1131-1135.

Small DM, Wang L, Mitsche MA. 2009. The adsorption of biological peptides and proteins at the oil/water interface. A potentially important but largely unexplored field. J Lipid Res 50 (Suppl): S329-S334.

Soni KG, Mardones GA, Sougrat R, Smirnova E, Jackson CL, Bonifacino JS. 2009. Coatomer-dependent protein delivery to lipid droplets. J Cell Sci 122: 1834-1841.

Spanova M, Czabany T, Zellnig G, Leitner E, Hapala I, Daum G. 2010. Effect of lipid particle biogenesis on the subcellular distribution of squalene in the yeast Saccharomyces cerevisiae. J Biol Chem 285: 6127-6133.

Stemberger BH, Walsh RM, Patton S. 1984. Morphometric evaluation of lipid droplet associations with secretory vesicles, mitochondria and other components in the lactating cell. Cell Tissue Res 236: 471-475.

Sturmey RG, O’Toole PJ, Leese HJ. 2006. Fluorescence resonance energy transfer analysis of mitochondrial:Lipid association in the porcine oocyte. Reproduction 132: 829-837.

Subramanian V, Rothenberg A, Gomez C, Cohen AW, Garcia A, Bhattacharyya S, Shapiro L, Dolios G, Wang R, Lisanti MP, et al. 2004. Perilipin a mediates the reversible binding of cgi-58 to lipid droplets in 3t3-11 adipocytes. J Biol Chem 279: 42062-42071.

Syed GH, Amako Y, Siddiqui A. 2010. Hepatitis c virus hijacks host lipid metabolism. Trends Endocrinol Metab 21: 33-40.

Sztalryd C, Bell M, Lu X, Mertz P, Hickenbottom S, Chang BH, Chan L, Kimmel AR, Londos C. 2006. Functional compensation for adipose differentiation-related protein (adfp) by tip47 in an adfp null embryonic cell line. J Biol Chem 281: 34341-34348.

Sztalryd C, Xu G, Dorward H, Tansey JT, Contreras JA, Kimmel AR, Londos C. 2003. Perilipin a is essential for the translocation of hormone-sensitive lipase during lipolytic activation. J Cell Biol 161: 1093-1103.

Szymanski KM, Binns D, Bartz R, Grishin NV, Li WP, Agarwal AK, Garg A, Anderson RG, Goodman JM. 2007. The lipodystrophy protein seipin is found at endoplasmic reticulum lipid droplet junctions and is important for droplet morphology. Proc Natl Acad Sci 104: 20890 20895.

Tai ES, Ordovas JM. 2007. The role of perilipin in human obesity and insulin resistance. Curr Opin Lipidol 18: $152-156$.

Tauchi-Sato K, Ozeki S, Houjou T, Taguchi R, Fujimoto T. 2002. The surface of lipid droplets is a phospholipid monolayer with a unique fatty acid composition. J Biol Chem 277: 44507-44512.

Thiele C, Spandl J. 2008. Cell biology of lipid droplets. Curr Opin Cell Biol 20: 378-385. 
Turro S, Ingelmo-Torres M, Estanyol JM, Tebar F, Fernandez MA, Albor CV, Gaus K, Grewal T, Enrich C, Pol A. 2006. Identification and characterization of associated with lipid droplet protein 1: A novel membrane-associated protein that resides on hepatic lipid droplets. Traffic 7: $1254-1269$.

van Manen HJ, Kraan YM, Roos D, Otto C. 2005. Single-cell raman and fluorescence microscopy reveal the association of lipid bodies with phagosomes in leukocytes. Proc Natl Acad Sci 102: 10159-10164.

Waltermann M, Hinz A, Robenek H, Troyer D, Reichelt R, Malkus U, Galla HJ, Kalscheuer R, Stoveken T, von Landenberg P, et al. 2005. Mechanism of lipid-body formation in prokaryotes: How bacteria fatten up. Mol Microbiol 55: $750-763$.

Walther TC, Farese RVJr. 2009. The life of lipid droplets. Biochim Biophys Acta 1791: 459-466.

Wan HC, Melo RC, Jin Z, Dvorak AM, Weller PF. 2007. Roles and origins of leukocyte lipid bodies: Proteomic and ultrastructural studies. FASEB J 21: 167-178.

Wang H, Wei E, Quiroga AD, Sun X, Touret N, Lehner R. 2010. Altered lipid droplet dynamics in hepatocytes lacking triacylglycerol hydrolase expression. Mol Biol Cell 21: 1991-2000.

Wanner G, Formanek H, Theimer RR. 1981. The ontogeny of lipid bodies (spherosomes) in plant cells: Ultrastructural evidence. Planta 151: 109-123.

Webb JL, Ravikumar B, Atkins J, Skepper JN, Rubinsztein DC. 2003. $\alpha$-synuclein is degraded by both autophagy and the proteasome. J Biol Chem 278: 25009-25013.

Welte MA. 2007. Proteins under new management: Lipid droplets deliver. Trends Cell Biol 17: 363-369.

Welte MA. 2009. Fat on the move: Intracellular motion of lipid droplets. Biochem Soc Trans 37: 991-996.
Welte MA, Cermelli S, Griner J, Viera A, Guo Y, Kim DH, Gindhart JG, Gross SP. 2005. Regulation of lipid-droplet transport by the perilipin homolog lsd2. Curr Biol 15: 1266-1275.

Windpassinger C, Auer-Grumbach M, Irobi J, Patel H, Petek E, Horl G, Malli R, Reed JA, Dierick I, Verpoorten N, et al. 2004. Heterozygous missense mutations in bscl2 are associated with distal hereditary motor neuropathy and silver syndrome. Nat Genet 36: 271-276.

Wolins NE, Quaynor BK, Skinner JR, Schoenfish MJ, Tzekov A, Bickel PE. 2005. S3-12, adipophilin, and tip47 package lipid in adipocytes. J Biol Chem 280: 19146-19155.

Yamaguchi T, Omatsu N, Morimoto E, Nakashima H, Ueno K, Tanaka T, Satouchi K, Hirose F, Osumi T. 2007. Cgi-58 facilitates lipolysis on lipid droplets but is not involved in the vesiculation of lipid droplets caused by hormonal stimulation. J Lipid Res 48: 1078-1089.

Yen CL, Stone SJ, Koliwad S, Harris C, Farese RVJr. 2008. Thematic review series: Glycerolipids. Dgat enzymes and triacylglycerol biosynthesis. J Lipid Res 49: 22832301.

Zechner R, Kienesberger PC, Haemmerle G, Zimmermann R, Lass A. 2009. Adipose triglyceride lipase and the lipolytic catabolism of cellular fat stores. J Lipid Res 50:3-21.

Zehmer JK, Bartz R, Bisel B, Liu P, Seemann J, Anderson RG. 2009. Targeting sequences of ubxd 8 and aam-b reveal that the er has a direct role in the emergence and regression of lipid droplets. J Cell Sci 122: 3694-3702.

Zimmermann R, Lass A, Haemmerle G, Zechner R. 2009. Fate of fat: The role of adipose triglyceride lipase in lipolysis. Biochim Biophys Acta 1791: 494-500.

Zweytick D, Athenstaedt K, Daum G. 2000. Intracellular lipid particles of eukaryotic cells. Biochim Biophys Acta 1469: $101-120$. 


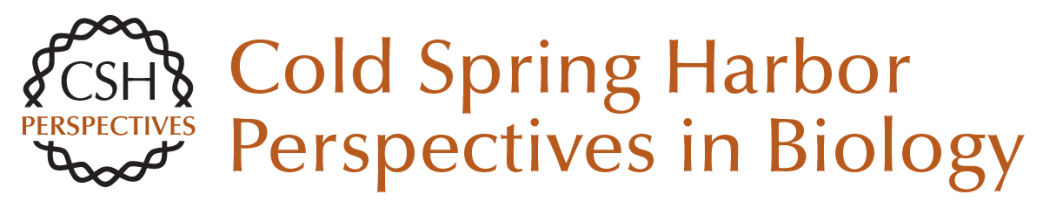

\section{Not Just Fat: The Structure and Function of the Lipid Droplet}

Toyoshi Fujimoto and Robert G. Parton

Cold Spring Harb Perspect Biol 2011; doi: 10.1101/cshperspect.a004838 originally published online January 26, 2011

\section{Subject Collection The Biology of Lipids}

Role of Lipids in Virus Replication Maier Lorizate and Hans-Georg Kräusslich

Model Answers to Lipid Membrane Questions Ole G. Mouritsen

\section{Glycosphingolipid Functions} Clifford A. Lingwood

Regulation of Cholesterol and Fatty Acid Synthesis

Jin Ye and Russell A. DeBose-Boyd

Lipid-Mediated Endocytosis

Helge Ewers and Ari Helenius

Fluorescence Techniques to Study Lipid

Dynamics

Erdinc Sezgin and Petra Schwille

Lysosomal Lipid Storage Diseases Heike Schulze and Konrad Sandhoff

Distribution and Functions of Sterols and Sphingolipids

J. Thomas Hannich, Kyohei Umebayashi and Howard Riezman
Membrane Organization and Lipid Rafts Kai Simons and Julio L. Sampaio

Shotgun Lipidomics on High Resolution Mass

Spectrometers

Dominik Schwudke, Kai Schuhmann, Ronny

Herzog, et al.

Glycosphingolipid Functions Clifford A. Lingwood

Phosphoinositides in Cell Architecture Annette Shewan, Dennis J. Eastburn and Keith Mostov

Synthesis and Biosynthetic Trafficking of Membrane Lipids

Tomas Blom, Pentti Somerharju and Elina Ikonen

Lipid Polymorphisms and Membrane Shape Vadim A. Frolov, Anna V. Shnyrova and Joshua Zimmerberg

Specificity of Intramembrane Protein-Lipid Interactions

Francesc-Xabier Contreras, Andreas Max Ernst, Felix Wieland, et al.

Dynamic Transbilayer Lipid Asymmetry Gerrit van Meer

For additional articles in this collection, see http://cshperspectives.cshlp.org/cgi/collection/

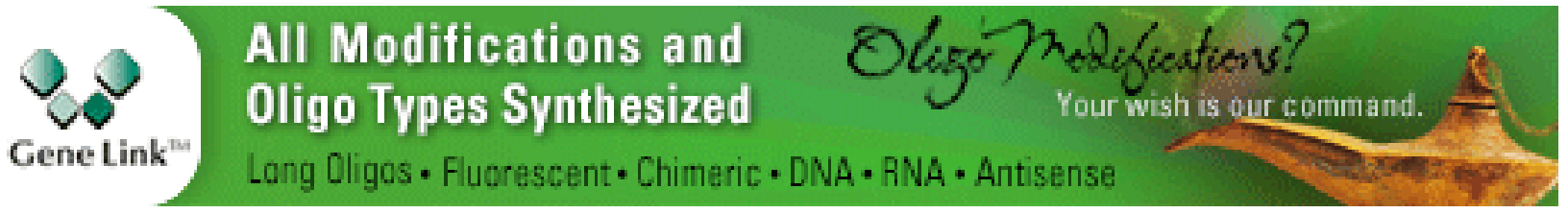

Copyright @ 2011 Cold Spring Harbor Laboratory Press; all rights reserved 